\title{
Impact of Journaling on Students' Self-Efficacy and Locus of Control
}

\author{
Krista K. Fritson, PsyD \\ Assistant Professor, Department of Psychology \\ University of Nebraska at Kearney
}

\begin{abstract}
While considerable research has examined the academic and cognitive value of journaling, little has examined the psychological impact of journaling on the personal development of college students. Research on cognitive-behavioral therapy indicates that journaling can have a positive impact on individuals' self-growth and intrapersonal characteristics. The purpose of this study is to examine the impact of classroom-based journaling on students' self-efficacy and locus of control. Students in two undergraduate courses were required to complete weekly journal assignments; one class received targeted information on cognitive-behavioral therapy (CBT) and one class did not. Students completed pre-, mid-, and postcourse assessments on self-efficacy, locus of control, and learning. Results revealed that self-efficacy scores for both groups significantly improved after the early journaling assignments; however, there were no differences between those who received direct $C B T$ instruction and those who did not. These findings indicate that journaling may have important psychological benefits above and beyond its expected academic and cognitive outcomes.
\end{abstract}

While post-secondary educators frequently implement new teaching strategies to improve their students' academic development, less attention has been devoted to understanding how academic activities influence students intrapersonally. Research in cognitive-behavioral therapy (CBT) reveals a variety of strategies and techniques that positively impact self-efficacy, locus of control and other psychological characteristics, although little information exists on the value of CBT strategies for non-clinical populations. This study seeks to apply the empirical findings from psychological research to examine the value of journaling, a popular CBT technique, on students' self-efficacy and locus of control.

Traditional post-secondary education is

While post-secondary educators frequently implement new teaching strategies to improve their students' academic development, less attention has been devoted to understanding how academic activities influence students intrapersonally. designed to enhance student engagement, promote content learning, encourage critical thinking, and increase students' intellectual growth. Many instructors aim to achieve these academic goals while simultaneously attempting to foster students' intrapersonal growth, self-reflection and personal insight. However, it is particularly challenging to design course assignments and activities that effectively address both the academic and psychological goals. Borrowing from research in clinical psychology, CBT strategies may provide a means of simultaneously encouraging advanced content knowledge and increased self-reflection. While there are a variety of effective CBT techniques, the current study focuses on the value of journaling due to the widespread use of journaling as an accepted academic strategy.

In clinical studies, journaling is often used to promote self-introspection, reflection, and change in the client's perceptions, behaviors and cognitions. Similarly, journaling is seen as a viable tool in academia to promote reflection on and articulation of students' thinking and problem solving strategies (Fogarty \& McTighe, 1993), to support students in effectively acquiring and transferring cognitive and metacognitive skills (Perkins, Simmons, \& Tishman, 1990), and to assist students in identifying and analyzing their deficits while improving problemsolving skill strategies (Clarke, Waywood, \& Stephens, 1993). Academic journaling

InSight: A Journal of Scholarly Teaching 
typically takes the form of dialogue or reflective narrative. Reflective journaling requires students to reflect on course information and their perceptions of the information, critically analyze information, and/or share how practical or field experiences relate to course information or life applications. Proponents of academic journaling believe that it is a non-traditional way for students to ground their personal experiences such as those in field or practicum experiences into course information, allows students to improve their writing skills, and promotes critical thinking for students (O'Connell \& Dyment, 2006). Current research by Dunlap (2006) also supports guided reflective journaling as a means to recognize students' changing perceptions as information is learned.

The specific nature of journaling assignments varies, depending on the academic setting. Journaling can be unstructured, allowing students to reflect on self-identified information from a course or experience. Conversely, journaling may be very structured with the instructor identifying specific topics and objectives related to students' journals. Regardless of the style of journaling, the primary aim is to have students contemplate and integrate information from courses to real-life experiences, promote critical thinking, and communicate their perceptions/experiences in a written manner.

In CBT, journaling may take many forms and is used as a means to assist clients in becoming more aware of their harmful behavior, establishing healthier coping skills, and incorporating change into their lives. Clients may be required to identify specific thoughts, their resultant feelings and behaviors, and journal about the impact of altering their thoughts. By using such strategies, individuals actively alter their behavior in attempt to improve their personal perspectives, mood, and daily functioning (Beck \& Beck, 1995). Significant research supports cognitive strategies such as journaling improve mood and functioning of depressed and anxious individuals (Nicholas, 2006). Journaling has been shown to improve clients' self-awareness, promote active reflection on clients' selves and make changes in clients' thoughts, perceptions, behaviors, and mood.

Self-efficacy and locus of control are two constructs associated with CBT strategies that may be involved in changing individuals' thoughts, behaviors, and emotions. Self-efficacy refers to individuals' personal belief about their ability to initiate, persist in, and be successful in behavior (Bandura, 1977, 1982, 1997). Selfefficacy has been shown to be an accurate predictor of success in a range of behaviors from smoking cessation to athletic endeavors to academic performance (Manstead \& Van-Eekelen, 1998; Sadri \& Robertson, 1993; Stajkovic \& Luthans, 1998). There is an established correlation between individuals' self-efficacy and their willingness to engage in and be successful in differing areas of life functioning (Bandura, 1997). Bandura recognized individuals' self-esteem, as well as how they attribute blame or credit, impacted their self-efficacy and engaging behaviors. Since self-esteem and attribution of events are also associated with mood and anxiety, it follows that they could be involved in changes that might occur in thoughts, behavior, and moods of students as a result of cognitive-behavioral information and activities.

Locus of control refers to individuals'

\section{Self-efficacy and locus of control are essential components for student success in an academic setting.}

perceptions about the underlying main causes of events in their lives (Rotter, 1966). Rotter believes locus of control is an important component to individuals' personality and largely predicts whether they attribute success and failure to things within their control or to external entities. According to Rotter, individuals typically fall on a continuum in their beliefs about what causes their actions. Individuals with a primarily internal locus of control believe that their own behavior drives their destiny; conversely, individuals with a primarily external locus of control believe that external forces are largely responsible for one's fate. As with self-efficacy, cognitive-behavioral strategies are believed to correlate with potential changes in individuals' locus of control. 
Self-efficacy and locus of control are essential components for student success in an academic setting. Improving students' self-efficacy enhances their ability to initiate, persist, and succeed with classroom activities; likewise, encouraging an internal locus of control helps to ensure that students take active responsibility for their learning. Thus, anything that faculty can do to facilitate learners' personal growth on these dimensions should translate into improved classroom performance and content-mastery.

\section{Current Investigation}

The aim of the present study is to investigate the impact of journaling on students' self-efficacy and locus of control. In addition, due to the academic context of the assignments, the study will also examine the impact of journaling on student learning and students' perceptions of the instructor and course. Because the existing literature on the psychological impact of journaling stems from research in $\mathrm{CBT}$, it is important to examine whether any psychological benefits of journaling are due to the simple process of self-reflection inherent in journaling activities or if there is something unique about CBT approaches to the journaling process. As such, the current study will compare the impact of journaling assignments where students were given explicit instruction in CBT versus journaling assignments where students had no explicit CBT instructions. It is hypothesized that participants who apply cognitive-behavioral strategies via journaling assignments will show enhanced selfefficacy, internal locus of control, academic success, and perceptions of the instructor and course when compared to the students who journal without cognitive-behavioral directions.

\section{Method}

\section{Participants}

The participants are 41 psychology student volunteers ranging in age from 19 to 44 years (29 females, 12 males, Age $M=21.3, S D=4.11$ ) from a public, mid-western university. Participants are all enrolled in one of two introductory level Abnormal Behavior and Society classes taught by the same instructor.

Each class was randomly assigned to either the CBT journaling or non-CBT journaling condition. The CBT journaling condition included 25 students (17 females, 8 males, mean age $=20.9$ ) who completed weekly written journals applying targeted cognitive-behavioral strategies to their personal experiences. One new cognitive-behavioral strategy was introduced and discussed for approximately 10 minutes each week throughout the semester. The non-CBT journaling condition included 16 students (12 females, 4 males, mean age $=21.8$ ) who completed weekly journals pertaining to any topic from the course textbook or class discussions. No cognitive-behavioral strategies were introduced or discussed beyond what is normally in the course.

\section{Materials}

All participants independently completed the following measures at the beginning of the course, midterm and end of the semester:

- Demographics Form. The demographic form included information on age, gender, academic year and GPA, college major, and estimated times they planned to study or studied for quizzes and exams for the course.

- $\quad$ Self-Efficacy Questionnaire (SEQ). The SEQ is a 23-question measure used to assess individuals' self-efficacy regarding their personal belief about their ability to initiate and persist in behavior (Sherer et al., 1982). This scale was established to measure individuals' General Self-Efficacy and individuals' Social Self-Efficacy. The 23 questions are answered on a 14point Likert Scale. 
- Locus of Control Scale. The Locus of Control Scale is a 10-item questionnaire used to measure whether individuals perceive themselves as having a more external or internal locus of control. It was developed by Rotter (1971) to assess individuals' beliefs that their destiny is controlled by themselves (internal) or factors outside of themselves (external).

- Grades. Participants/students final percentage grade for the course was used as the measure of academic outcome.

- Perception of Professor Form. This questionnaire included 10 questions on a 5-point Likert Scale to assess individuals' perception of their professor. This form was administered at mid-term and the end of the semester.

- Course/Professor Evaluation Form. This questionnaire included 15 questions on a 5-point Likert Scale to assess individuals' evaluation of the course and professor's performance. This form was administered at midterm and the end of the semester.

- Cognitive-Behavioral Education/Discussion. Each week, the CBT journaling students were introduced to one new cognitive-behavioral strategy and given an assignment to journal regarding that concept and explain at least two real life examples of its use during their lives. Refer to Appendix A for examples of the cognitive-behavioral strategies introduced in the course. Students were encouraged to apply the concept to their current life situation, though they had the freedom to conceptualize regarding any life experiences. The length of the journal assignment was at least three quarters of a page. The journal assignments were due the following week when the instructor would reiterate the concept, then teach a new cognitive-behavioral strategy. Each assignment was included in the students' grade; credit was awarded on a completion-only basis. Refer to Appendix B for an example of the journal assignments for the CBT journaling group. The non-CBT journal students were asked to write an equivalent journal entry regarding any class or text topic for the week. These assignments were assigned and submitted in the same fashion as the CBT journaling condition. Refer to Appendix $C$ for an example of the journal assignments for the non-CBT journal group.

\section{Procedure}

A brief description of the study was given at the beginning of the class. All participants from both conditions then completed the packet of questionnaires including the above-described measures minus the Perception of Professor Form and the Course/Professor Evaluation Form (since the participants had not had adequate time to evaluate those factors). The two classes were then taught using the same text, syllabus, curriculum, and lecture-discussion format. The only difference between the two classes was in the nature of the journal activities; the CBT journaling class received the 10 minute weekly discussion on cognitivebehavioral strategies along with the journal assignment, while the non-CBT journaling class received only the journal assignment. At midterm and the end of the semester, all participants completed the packet of questionnaires again, now including the Perception of Professor Form and the Course/Professor Evaluation Form. The students were then debriefed regarding the research project.

\section{Results}

A $2 \times 3$ mixed-design ANOVA was calculated to examine the effects of journaling (CBT or non-CBT) and time (beginning of course, midterm and end of course) on Self-Efficacy. The main effect for time was significant $(F(1,39)=82.89$, $p<.001)$, but the main effect for type of journaling was not significant $(F(1,39)=$ .006 , n.s.). The interaction between type of journaling and timing was not significant $(F(1,39)=2.51, n . s$.$) . For the main effect of time, a repeated measures$ 
ANOVA indicated that the significant change occurred from the beginning of the semester to the midterm test regarding Self-Efficacy $F(1,39)=104.65, p<.01$. The results of the ANOVA indicated no significant differences between the midterm and end-of-semester measures $F(1,39)=3.18$, n.s. These results indicate that there was significant positive change in self-efficacy in all participants in the study, regardless of the type of journaling. Further, the results show the change was most significant at midterm, and there was not a significant change in self-efficacy between the midterm and end of the semester.

Additional ANOVAs examining the impact of journaling (CBT or non-CBT) by timing (beginning, midterm and end of the semester) on locus of control, perception of the instructor, course evaluation, and grades did not show any significant differences between groups or time.

\section{Discussion}

The results indicate that all students showed significant improvement in self-efficacy, regardless of the type of journaling they engaged in. Specifically, the data suggest that all students' self-efficacy improved from the beginning of the course to the midterm, regardless of whether or not they received additional information on cognitive-behavioral techniques. These results do not support the hypothesis that students completing cognitive-behavioral instruction and journaling would show improvements in self-efficacy over journaling without specific CBT information.

These findings suggest that journaling, regardless of the nature of the journal, may have positively impacted students' self-efficacy. Given that previous research indicates reflective journaling is an effective way to impact students' problem-solving, thought articulation, and exploration of metacognition (Dunlap, 2006), this study suggests journaling may play a significant role in affecting students self-efficacy. However, as is the nature of classroom-based research, the relationship between journaling and self-efficacy may be clouded by other instructional variables such as instructor style or course content.

Other results exploring students' locus of control, grades, perception of the instructor, attendance, and course evaluation did not support the hypotheses that individuals receiving the cognitive-behavioral education and journaling would demonstrate significantly better scores than the students not receiving the CBT assignments. In contrast, the journaling implemented in this course did not have an impact on any of these factors. It is important to note that the current study did not implement a pure control condition (in which there was no journaling), so it is still unclear on the overall impact of journaling on these dimensions.

It is important to note that the findings from this pilot study should serve as a basis for ongoing research into the psychological impact of academic journaling rather than a conclusive finding on the role of journaling in college classrooms. Because this study was conducted within the constraints of a live classroom, the study balanced experimental control with the demands of the classroom. Future research should isolate variables such as instructor, course content and journaling in an attempt to replicate the findings and/or identify which variables may have accounted for the change in students' self-efficacy. Exploration of the timeline in which the change in self-efficacy occurred could also be included in future studies.

Self-efficacy research strongly indicates that self-efficacy is a good predictor of successful task completion, correlates with levels of performance, and is related to self-esteem (Manstead \& Van-Eekelen, 1998; Sadri \& Robertson, 1993; Stajkovic \& Luthans, 1998). Given the potential positive ramifications of improving students' self-esteem, the incorporation of journaling in the college classroom may provide students with far-reaching benefits beyond simple mastery of course 
content. The psychological value of journaling mandates further study regarding how journaling and teaching variables impact students' intrapersonal characteristics.

Though this pilot study is based in psychology, the value of the findings is relevant to all disciplines. While all faculty actively promote content mastery, it can be argued that we should also focus on the intrapersonal and psychological growth of our students. As indicated by this study, academic journaling may be one means of simultaneously fostering the academic and psychological growth of students. Virtually all disciplines can incorporate journaling into the curriculum to improve academic variables as well as positively impact self-efficacy. To effectively utilize journaling to encourage students' intrapersonal growth, students' journal assignments should include the following aspects:

1. Identify a life experience/situation which exemplifies a concept from their text/course material

2. Reflect on various perspectives when a new concept or idea is introduced

3. Consider a perspective opposite of what they truly believe regarding a particular concept or matter

Instructors should allow students flexibility while still providing structure to promote critical thinking and self-exploration. This study's findings provide an opportunity for a range of disciplines within higher education to positively impact students' academic needs, critical thinking skills, and intrapersonal attitudes/beliefs that promote success in life functioning.

\section{References}

Bandura, A. (1977). Self-efficacy:

Toward a unifying theory of behavioral change. Psychological Review, 84, 191-215.

Bandura, A. (1982). Self-efficacy mechanisms in human agency. American Psychologist, 37, 122-147.

Bandura, A. (1997). Self-efficacy: The exercise of control. New York: W. $\mathrm{H}$. Freeman.

Beck, J. \& Beck, A. T. (1995).

Cognitive therapy: Basics and beyond. New York: Guilford Press.

Clarke, D., Waywood, A., \& Stephens, M. (1993). Probing the structure of mathematical writing. Educational Studies in Mathematics, 25, 235-250.

Dunlap, J. C. (2006). Using guided reflective journaling activities to capture students' changing perceptions. TechTrends, 50(6), 2026.
Fogarty, R. \& McTighe, J. (1993). Educating teachers for higher order thinking: The three-story intellect. Theory into Practice, 32(3), 161-169.

Manstead, A. S. R. \& Van-Eekelen, S. A. M. (1998). Distinguishing between perceived behavioral control and selfefficacy in the domain of academic intentions and behaviors. Journal of Applied Social Psychology, 28, 13751392.

Nicholas, A. B. (2006). An introduction to the psychotherapies. New York: Oxford University Press.

O'Connel, T. \& Dyment, J. (2006).

Reflections on using journals in higher education: a focus group discussion with faculty. Assessment and Evaluation in Higher Education, 31(6), 671-691.

Perkins, D., Simmons, R., \& Tishman, S. (1990). Teaching cognitive and metacognitive strategies. Journal of Structured Learning, 10(4), 285-303. 
Rotter, J. (1966). Generalized expectancies for internal versus external control of reinforcements. Psychological Monographs, 80, 609.

Rotter, J. (1971, June). Locus of control scale. Psychology Today, 42.

Sadri, G. \& Robertson, I. T. (1993). Self-efficacy and work-related behavior: A review and metaanalysis. Applied Psychology, 42, 139-152.
Sherer, M., Maddux, J. E., Mercadante, B., Prentice-Dunn, S., Jacobs, B. \& Rogers, R.W. (1982). The self-efficacy scale: Construction and validation. Psychological Reports, $51,663-671$.

Stajkovic, A. D. \& Luthans, F. (1998). Self-efficacy and work-related performance: A meta-analysis. Psychological Bulletin, 124, 240-261.

Krista Fritson earned her PsyD from the Forrest Institute of Professional Psychology, MS from Fort Hays State University and BS from the University of Nebraska at Kearney. Dr. Fritson joined the University of Nebraska at Kearney as an Assistant Professor after serving as a part-time lecturer for two years. At UNK, Dr. Fritson teaches the clinical track courses, abnormal psychology, and general psychology. Additionally, Dr. Fritson continues to work as a Clinical Psychologist providing clinical consultation and services to all age groups and many diagnoses; her specialization is working with children, adolescents, and families. With over 21 years of experience working in the mental health field, Dr. Fritson enjoys the opportunity to engage college students and promote the field of psychology. 


\section{Appendix A: Sample Cognitive Behavioral Strategies}

1. Cognitive Distortions (Aaron Beck)

Description: For each of the cognitive distortions, the participants were given a definition and examples of its use, they then identified times in which they use the distortion at least twice that week and journal about it. Students were required to journal about two distortions as assigned by the instructor. The cognitive distortions included the following:

- $\quad$ All or Nothing: The tendency to see situations as either black or white.

- Overgeneralizations: Drawing a conclusion based on a single event or small piece of evidence.

- $\quad$ Filters: We only see what we want to see in a situation.

- Magnification: The propensity to make mountains out of molehills.

- Labeling: Putting tags on people or situations that are one dimensional.

- Jumping to Conclusions: Making snap judgments or assumptions.

- Shoulds: Following an inflexible list of rules regarding how the world at large "should" behave.

- Blaming: Constantly pointing the finger of blame at others or yourself.

- Disqualifying: A person reverses a compliment so that it really becomes a put down.

- Mistake of Control: Thoughts of feeling totally helpless or that you must be in complete control of a given situation.

2. Assertiveness Skills

Description: The four communication styles of Passive, Aggressive, Assertive, and Passive-Aggressive were discussed in class. The students described two incidents of these styles in their journals.

3. Progressive Relaxation

Description: Progressive relaxation strategies were described and briefly demonstrated. The students described two incidents of using this strategy during the week in their journals.

4. Thought-Stopping/Self-Talk Training

Description: Thought stopping/self-talk strategies were described and demonstrated in class. The students described two incidents of using these strategies during the week in their journals.

5. Visual Imagery

Description: Visual imagery strategies were described and demonstrated in class. The students described two incidents of using these strategies during the week in their journals.

\section{Appendix B: Sample Cognitive-Behavioral Journal Assignment}

List two examples in which you have caught yourself doing "all or nothing" thinking. Fill in the situation, thoughts/feelings section, new thought, and changes according to directions below (do this for 2 examples). Write 4-8 sentences (at least $3 / 4$ page) about your thoughts about all or nothing thinking and how it impacts you and/or others.

All or Nothing: The tendency to see situations as either black or white.

\begin{tabular}{|l|l|l|l|l|}
\hline $\begin{array}{c}\text { Thought } \\
\text { Distortion }\end{array}$ & Situation & Thoughts/Feelings & New thought & \multicolumn{1}{c|}{ Changes } \\
\hline $\begin{array}{l}\text { All or } \\
\text { nothing } \\
\text { thinking }\end{array}$ & $\begin{array}{l}\text { Write } \\
\text { description } \\
\text { of situation }\end{array}$ & $\begin{array}{l}\text { Write your } \\
\text { thoughts/ } \\
\text { feelings about } \\
\text { situation }\end{array}$ & $\begin{array}{l}\text { Alter your } \\
\text { thought from all } \\
\text { or nothing to } \\
\text { different type of } \\
\text { thinking }\end{array}$ & $\begin{array}{l}\text { What do } \\
\text { you think } \\
\text { and feel } \\
\text { now....? }\end{array}$ \\
\hline
\end{tabular}


Appendix C: Sample Journal Assignment for Non-Cognitive-Behavioral Journaling

Journal about your impressions, beliefs, ideas regarding chapters 1 and 2 , possibly chapter 3 , of your text. Describe in about 6-8 sentences (at least 3/4 page). Be sure it is related to topics we have discussed and that are in your text. 